\title{
Is There a Role for Probiotics in Liver Disease?
}

\author{
Robert S. Lo, Andrew S. Austin, and Jan G. Freeman \\ Liver Unit, Royal Derby Hospital, Derby DE22 3NE, UK \\ Correspondence should be addressed to Jan G. Freeman; j.freeman115@btinternet.com
}

Received 30 July 2014; Accepted 27 September 2014; Published 11 November 2014

Academic Editor: Pietro Vajro

Copyright (C) 2014 Robert S. Lo et al. This is an open access article distributed under the Creative Commons Attribution License, which permits unrestricted use, distribution, and reproduction in any medium, provided the original work is properly cited.

Intestinal microbiota plays an important role in health and disease. Alteration in its healthy homeostasis may result in the development of numerous liver disorders including complications of liver cirrhosis. On the other hand, restoration and modulation of intestinal flora through the use of probiotics is potentially an emerging therapeutic strategy. There is mounting evidence that probiotics are effective in the treatment of covert and overt hepatic encephalopathy, as well as in the prevention of recurrence of encephalopathy. The beneficial effect of probiotics also extends to liver function in cirrhosis, nonalcoholic fatty liver disease, and alcoholic liver disease. On the other hand, data associating probiotics and portal hypertension is scanty and conflicting. Probiotic therapy has also not been shown to prevent primary or secondary spontaneous bacterial peritonitis. Larger clinical studies are required before probiotics can be recommended as a treatment modality in liver diseases.

\section{Introduction}

Probiotics are defined by the World Health Organisation as live microorganisms that confer a health benefit on the host when administered in adequate amounts [1]. The concept of probiotics is not a novel entity. More than a century ago, Nobel Prize winner Eli Metchnikoff suggested that the long life of Bulgarian peasants was the result of their consumption of fermented milk products [2]. He went on to introduce in his diet sour milk fermented with the bacteria he called "Bulgarian Bacillus" and found his health benefited [3]. In actual fact, the practice of using probiotics in daily lives for health enrichment has been around for millenniums. Even in the ancient Greek and Roman empires, the use of cheese and fermented products was highly recommended [4]. Although the term "probiotic" was credited to Lilly and Stillwell [5] who in 1965 described probiotics as microorganisms that have effects on other microorganisms, the modern terminology and definition of probiotics was coined by Parker [6] who in 1974 defined probiotics as organisms and substances that have a beneficial effect on the host animal by contributing to its intestinal microbial balance. Consumption of modern era probiotics has been prevalent for decades even before the proper terminology was well established. As early as 1930, Shirota in Japan started to culture lactic acid bacteria (Lactobacillus casei strain Shirota) which he subsequently introduced into the market as Yakult in 1935 [7]. Today Yakult is marketed in 33 countries and 30 million bottles are consumed on a daily basis.

This review of probiotic use and liver diseases focuses on the following aspects: prevention of infection, hepatic encephalopathy, liver function in cirrhosis, nonalcoholic fatty liver disease, alcoholic liver disease, and portal hypertension.

\section{Intestinal Microflora}

There is a strong relationship between liver and the gut-the so-called Liver-Gut axis. The gut supplies blood to the portal system and intestinal blood content activates liver functions. On the other hand, the liver secretes bile and influences intestinal function [8].

Intestinal microflora forms a complex ecological system. It contains a large amount of microbes that weigh more than $1 \mathrm{~kg}$. This quantity exceeds the number of cells in the human body 10 -fold. The microbial community of the intestine consists of more than 500 species, most of which have not been cultivated, and many have yet to be identified. The intestinal microflora contains both bacteria that are fixed in the intestine (autochthonous, resident) and bacteria that only pass through the intestine (transient allochthonous) [9]. Most of the bacteria in the intestine form an anaerobic 
bioreactor that helps to digest difficult polysaccharides and synthesizes micronutrients including vitamins and shortchain fatty acids. The fermentation products of these bacteria can provide up to $10 \%$ of the daily energy needed by an individual [10].

The intestinal microflora has a variety of important physiological functions. It produces vitamins, degrades bile acids, digests nutrients, and forms important barrier against pathogens by producing local and general immunity [11].

In patients with liver cirrhosis, abnormal colonisation of the small intestine with colonic bacteria is well established. At least 50\% have intestinal bacterial overgrowth. This is in comparison with healthy individuals who have only small amount of these bacteria in the small intestine. The main causes are thought to be hypochlorhydria, a decrease in IgA secretion, a decrease in intestinal motility, and malnutrition. In the clinical setting, increasing small intestinal motility pharmacologically with Cisapride has been shown to reduce bacterial overgrowth in patients with cirrhosis [12]. With such a close relationship between the liver and the gut flora, it is not surprising that many have postulated a role for gut barrier in the pathogenesis of liver diseases and its complications.

\section{Bacterial Translocation}

Bacterial translocation is defined as the migration of bacteria from the intestinal lumen to mesenteric lymph nodes of other extraintestinal sites [13]. The most effective bacteria to translocate to the mesenteric lymph nodes are Gramnegative members of the Enterobacteriaceae family such as Escherichia coli and Klebsiella spp, enterococci, and other streptococci species [14]. In an animal study, the prevalence of bacterial translocation to mesenteric lymph nodes is around $40 \%$ in cirrhotic rats with ascites [15] and around $80 \%$ in such animals with spontaneous bacterial peritonitis [16]. Available evidence has suggested that bacteria isolated from the mesenteric lymph nodes are genetically identical to strains causing spontaneous bacterial peritonitis (SBP) in the same animal [17]. In patients undergoing liver transplantation or liver resection, positive mesenteric lymph node culture for enteric bacteria was found in nearly $31 \%$ of Child-Pugh class C cirrhotics, which was 5 times higher than in Child Pugh Class A or B [18]. In cirrhotic patients undergoing partial hepatectomy, almost $20 \%$ were found to have positive mesenteric lymph node culture, and most of the postoperative infections were due to the same bacteria [19].

Bacterial DNA is found in approximately one-third of cirrhotic patients with portal hypertension and culture negative ascites, with Escherichia coli being the most frequently identified bacterial species [20]. The presence of bacterial DNA is associated with increased local levels of proinflammatory cytokines, which may be clinically significant [21]. Endotoxaemia is also postulated to increase portal pressure and impair haemostasis [22], as well as helping in the induction of variceal bleeding [23].

The pathogenesis of bacterial translocation in cirrhosis is complex. Apart from intestinal bacterial overgrowth, cirrhotics also exhibit changes in intestinal mucosa and intestinal immunity. Nitric oxide contributes to the morphological changes of the intestinal wall as it dilates tight junctions in cultured intestinal epithelial cells [24]. This represents the breaching of the first line of mucosal defence against paracellular absorption and hence the increased potential for bacterial translocation. Dilatation of the intercellular space below tight junctions, which is the second line of defence against paracellular absorption, also occurs in cirrhotics [25]. Thick-walled, dilated capillaries together with oedema of the lamina propria, fibromuscular proliferation, a reduced villous/crypt ratio, and thickened muscularis mucosa in the small bowel are found in cirrhotics [26] and have been proposed to play a role in bacterial translocation [27]. In addition intestinal immunity is also compromised. An animal study demonstrated an increased number of intraepithelial lymphocytes with markedly impaired proliferative activity and capacity for production of interferon- $\gamma$, correlating with increased bacterial translocation [28]. To summarise, the main mechanisms leading to bacterial translocation are bacterial overgrowth, a deficit in the local immune response of the mucous membrane, a decrease in phagocytic activity of macrophages as well as neutrophils, and an increase in the permeability of the intestinal barrier [29].

\section{Probiotics: Mechanisms of Benefit}

Mechanisms for the benefits of probiotics are not completely understood. However, four general benefits have been described [30]:

(1) suppression of growth, epithelial binding, or invasion by pathogenic bacteria [31],

(2) improvement of intestinal barrier function [32],

(3) modulation of the immune system; these include the inducement of protective cytokines such as IL-10 [33] and TGF-beta and suppression of proinflammatory cytokines such as TNF [34]; suppression of T-Helper 1 cells migration has also been described [35],

(4) modulation of intestinal pain perception by inducing expression of microopioid and cannabinoid receptors [36].

\section{Prevention of Infection}

Spontaneous bacterial infections such as SBP and bacteraemia are common in hospitalised cirrhotic patients. They also correlate with the severity of liver cirrhosis. These infections are associated with significant morbidity and mortality. For example, the prevalence of SBP in cirrhotic hospitalised patients with ascites is as high as 30\% [37], and despite aggressive therapy, 1 in 5 patients still die from SBP [38].

The causal link between bacterial translocation and SBP has been well demonstrated [17]. Probiotic usage in this setting is attractive because of its ability to modulate gut flora, favouring protective anaerobic organisms, and also because of its effects in promoting gut barrier function [39]. Probiotic supplementation increases resistance to enteric infection in IL-10 deficient mice [17]. In clinical studies, probiotics have 
demonstrated efficacy in reducing endotoxaemia in cirrhotics [40], which is an indicator of the bacterial translocation, by reducing the viable counts of potentially pathogenic Grampositive and Gram-negative gut flora in patients with cirrhosis [41]. Probiotics also reduce infections after orthotopic liver transplantation [42].

Current literature, albeit scanty, does not support the notion that probiotics prevent the occurrence of SBP. Using cirrhotic rats with ascites, probiotics failed to prevent bacterial translocation and ascitic fluid infection in spite of successful intestinal colonisation [43]. A recent clinical study showed that the addition of probiotics to norfloxacin did not improve its efficacy in preventing primary or secondary SBP or in reducing the mortality in cirrhotic patients with ascites [44].

\section{Hepatic Encephalopathy}

Gut microflora-derived ammonia has been widely recognised as the major contributor to the pathogenesis of hepatic encephalopathy. Modulating the intestinal flora pharmacologically remains the mainstay of treatments currently. This includes lactulose and nonabsorbable antibiotics such as neomycin and rifaximin.

As early as 1965, the idea of populating the colonic lumen with non-urease-producing bacteria as a treatment for hepatic encephalopathy was first put to test. An uncontrolled study suggested that high oral doses of Lactobacillus acidophilus might have a beneficial effect in patients with decompensated cirrhosis and hepatic encephalopathy [45]. Subsequently Lactobacillus acidophilus was shown to offer clinical improvement in encephalopathic patients refractory to neomycin alone [46]. Probiotics have been shown to reduce serum ammonia levels and result in improvement in various neurocognitive tests, as well as improvements in mental status [47].

A combination of prebiotics and probiotics (symbiotic approach) improved minimal hepatic encephalopathy, as well as reducing Gram-negative organisms in decompensated cirrhotics. A secondary end point for patients receiving symbiotic therapy was an improvement in overall liver function, as measured by the Child-Pugh score [48]. Similarly Bifidobacterium longum use in cirrhotic patients improves both minimal [49] and overt [50] hepatic encephalopathy. The use of probiotics in common clinical practice, however, requires further studies. A recent Cochrane review concluded that current available trials suffered from a high risk of bias and play of chance [51]. Although probiotics did appear to reduce plasma ammonia concentration, probiotics could not be concluded to be efficacious in altering clinically relevant outcomes.

The efficacy of probiotics in compensated cirrhotic patients with minimal hepatic encephalopathy has been studied. Treatment with probiotics preparation containing Lactobacillus acidophilus, Lactobacillus rhamnosus, Bifidobacterium longum, and Saccharomyces boulardii failed to produce any significant improvement in the various parameters assessed in patients with minimal hepatic encephalopathy, when compared with placebo [52]. Contrary to these studies, another study produced contrasting results demonstrating that three months of probiotics administration with VSL\#3, which is a cocktail of probiotics, was effective in preventing $\mathrm{HE}$ in patients with cirrhosis as it significantly reduced levels of arterial ammonia, SIBO, and orocaecal transit time together with increased psychometric hepatic encephalopathy scores, compared with baseline [53].

The role of probiotics in secondary prophylaxis of HE has also been examined. Compared to placebo, treatment with probiotics conferred the same significant beneficial effect as lactulose in reducing $\mathrm{HE}$ recurrence over a 12 -month followup [54].

\section{Liver Function in Cirrhosis}

Available studies suggest that probiotic therapy may improve liver function parameters in cirrhotic patients. In the study of synbiotic therapy described earlier [48], improvement of Child-Pugh class was recorded in nearly half the patients randomised to taking synbiotic therapy. The authors speculated that the improvement was secondary to the reduction in serum endotoxin levels. Using Escherichia coli Nissle, similar, but statistically less robust, results were achieved [40]. Patients treated with this probiotic for 42 days demonstrated a trend towards lower endotoxin levels and improvement in Child-Pugh score, although they were not statistically significant. Improvement in serum liver tests and also reduction in proinflammatory cytokines have been observed in nonalcoholic steatohepatitis related cirrhotics using VSL\#3 [55].

On the other hand, in patients with primary sclerosing cholangitis, treatment with a probiotics cocktail containing four Lactobacillus and two Bifidobacillus strains did not improve clinical symptoms or liver function tests [56]. The authors attributed this lack of efficacy to the fact that all the PSC patients in the study were already in remission for their IBD, with limited scope for further improvement in IBD, and therefore PSC. As the majority of patients with PSC have concurrent inflammatory bowel disease (IBD) [57], toxic substances originating from the inflamed gut may also be the culprit for damaging the liver and biliary trees. It has already been established that probiotics are beneficial for IBD [58] and pouchitis [59]. It is therefore highly plausible that the same beneficial effect might extend to PSC. Nevertheless larger clinical studies are required before any conclusion can be drawn.

\section{Nonalcoholic Fatty Liver Disease}

Evidence in animal studies shows that intestinal bacterial overgrowth plays a significant role in the pathogenesis of nonalcoholic fatty liver disease (NAFLD) [60]. Furthermore, obese patients with bacterial overgrowth after jejunoileal bypass surgery experienced rapid worsening of their NAFLD [61], suggesting a causal link. Endotoxaemia worsens NAFLD by stimulating hepatic Kupffer cells to produce TNF- $\alpha$ which stimulates liver fibrosis [62]. 
Loguercio et al. demonstrated improvement in serum liver function tests and also reduction in proinflammatory cytokines in nonalcoholic steatohepatitis related cirrhotics using VSL\#3 [55]. A Cochrane systemic review in 2007 concluded that, due to the lack of randomised controlled trials, the use of probiotics in NAFLD can neither be supported nor refuted [63]. Subsequent to that, Solga and Diehl examined four patients with NAFLD and assessed their liver fat after 4 months of VSL\#3 therapy [64]. Disappointingly they found that all four patients experienced increase in liver fat as measured by proton magnetic resonance spectroscopy. More recently it has been shown that probiotics improve liver aminotransferases levels and reduce lipopolysaccharide levels in patients with NAFLD, although anthropometric parameters and cardiovascular risk factors remained unchanged after treatment $[65,66]$. A larger study compared probiotics and fructooligosaccharides to life style changes in NAFLD with the probiotics arm significantly reducing TNF- $\alpha$, CRP, serum AST levels, homeostasis model assessment of insulin resistance, serum endotoxin, steatosis, and the NASH activity index [67]. Long term use of probiotics may significantly reduce liver fat and serum aspartate aminotransferases [68]. Taking into account these newer studies, a recent metaanalysis concluded that probiotic therapies can reduce liver aminotransferases, total cholesterol, and TNF- $\alpha$ and improve insulin resistance in NAFLD patients [69]. However, these conclusions should be interpreted cautiously as the total number of patients involved is small, some patients are children, and the results are not based on histology, which is the gold standard for the diagnosis of NASH.

\section{Alcoholic Liver Disease}

Alcoholic steatohepatitis and severe alcoholic liver disease (ALD) occur in $30 \%$ of heavy drinkers [70], suggesting that other factors may also play a causative role. The pathogenesis of ALD is a dynamic and unknown process characterized by several interactions that involve immune system and metabolic intermediates of alcohol [71]. This includes the ethanol metabolism-associated oxidative stress, abnormal methionine metabolism, ethanol-mediated induction of leakage of gut endotoxins, and activation of Kupffer cells [72-74]. Chronic alcoholism is also associated with higher levels of Proteobacteria (Gram-negative bacteria which include several pathogenic species such as Salmonella and Escherichia) and lower abundances of Bacteroidetes [75]. The resultant endotoxaemia triggers the proinflammatory pathways causing alcoholic steatohepatitis.

Treatment with Escherichia coli Nissle probiotics has been shown to restore the intestinal microflora including Lactobacilli and Bifidobacilli, to reduce endotoxaemia, and to improve liver function [40]. This beneficial effect is confirmed in another larger study using a probiotic preparation containing Bifidobacterium bifidum and Lactobacillus plantarum [76]. Emerging data has also shown a beneficial effect of Lactobacillus casei Shirota in restoring neutrophil phagocytic capacity [77], a marker associated with increased risk of infection and mortality in ALD [78].

\section{Portal Hypertension}

Bacteria translocation plays a role in increasing portal pressure by contributing to the exacerbation of the hyperdynamic circulatory state and the increase in hepatic vascular resistance [79].

Utilising the measurement of hepatic venous pressure gradient (HVPG), relationships between portal hypertension and probiotics have been investigated. Use of adjunctive probiotics (VSL\#3) increased the HVPG response rate (percentage of patients having a decrease from baseline of $\geq 20 \%$ or to $\leq 12 \mathrm{~mm} \mathrm{Hg}$ ) compared with propranolol alone and was similar to the response with adjunctive antibiotics. The mean fall in HVPG was greater with either adjunctive probiotics or adjunctive antibiotics than with propranolol alone [80]. A 6-week administration of VSL\#3 resulted in reductions of the HVPG, as well as in the improvement of systemic haemodynamics including cardiac index and mean arterial pressure [81].

Data in this area is, however, conflicting. Two studies utilising VSL\#3 did not reduce portal pressure in patients with compensated or decompensated cirrhosis. Furthermore, there were no significant changes in the stool microbiota evaluated by terminal restriction fragment length polymorphism, before and after therapy $[79,82]$.

\section{Potential Risk}

Although probiotics are generally well tolerated, even among cirrhotic patients [77], it is not without risk especially in patients with severe illness or in those who are immunocompromised. A study of patients with predicted severe acute pancreatitis given probiotic prophylaxis with a cocktail of six different bacteria was associated with an increased risk of mortality [83].

\section{Conclusion}

There is growing recognition that alteration of gut microbiota has a causative effect on the pathogenesis of numerous liver conditions including complications of liver cirrhosis. As a consequence, there is an increasing interest in the use of probiotics in preventing and treating these conditions. However, the role of probiotics in this context remains controversial. Emerging data are encouraging especially in the field of hepatic encephalopathy and NASH, although further studies are required before probiotics can be included in the respective treatment algorithms.

\section{Conflict of Interests}

The authors have no potential conflict of interests.

\section{References}

[1] 2014, http://www.who.int/foodsafety/publications/fs_management/en/probiotics.pdf.

[2] E. Metchnikoff, The Prolongation of Life: Optimistic Studies, Putman's Sons, New York, NY, USA, 1908. 
[3] R. B. Vaughan, "The romantic rationalist: a study of Elie Metchnikoff," Medical History, vol. 9, pp. 201-215, 1965.

[4] M. R. Gismondo, L. Drago, and A. Lombardi, "Review of probiotics available to modify gastrointestinal flora," International Journal of Antimicrobial Agents, vol. 12, no. 4, pp. 287-292, 1999.

[5] D. M. Lilly and R. H. Stillwell, "Probiotics: growth-promoting factors produced by microorganisms," Science, vol. 147, no. 3659, pp. 747-748, 1965.

[6] R. B. Parker, "Probiotics, the other half of the antibiotic story," Animal Nutrition and Health, vol. 29, pp. 4-8, 1974.

[7] Yakult Honsha Co., 2014, http://www.yakult.co.jp/english/.

[8] S. Zeuzem, "Gut-liver axis," International Journal of Colorectal Disease, vol. 15, no. 2, pp. 59-82, 2000.

[9] J. M. Saavedra and A. Tschernia, "Human studies with probiotics and prebiotics: clinical implications," British Journal of Nutrition, vol. 87, supplement 2, pp. S241-S246, 2002.

[10] A. J. Macpherson and N. L. Harris, "Interactions between commensal intestinal bacteria and the immune system," Nature Reviews Immunology, vol. 4, no. 6, pp. 478-485, 2004.

[11] M. C. Abt and D. Artis, "The intestinal microbiota in health and disease: the influence of microbial products on immune cell homeostasis," Current Opinion in Gastroenterology, vol. 25, no. 6, pp. 496-502, 2009.

[12] A. Pardo, R. Bartolí, V. Lorenzo-Zúniga et al., "Effect of cisapride on intestinal bacterial overgrowth and bacterial translocation in cirrhosis," Hepatology, vol. 31, no. 4, pp. 858-863, 2000.

[13] R. D. Berg and A. W. Garlington, "Translocation of certain indigenous bacteria from the gastrointestinal tract to the mesenteric lymph nodes and other organs in a gnotobiotic mouse model," Infection and Immunity, vol. 23, no. 2, pp. 403411, 1979.

[14] E. K. Steffen, R. D. Berg, and E. A. Deitch, "Comparison of translocation rates of various indigenous bacteria from the gastrointestinal tract to the mesenteric lymph node," The Journal of Infectious Diseases, vol. 157, no. 5, pp. 1032-1038, 1988.

[15] C. Guarner, B. A. Runyon, S. Young, M. Heck, and M. Y. Sheikh, "Intestinal bacterial overgrowth and bacterial translocation in cirrhotic rats with ascites," Journal of Hepatology, vol. 26, no. 6, pp. 1372-1378, 1997.

[16] J. M. Llovet, R. Bartolí, R. Planas et al., "Bacterial translocation in cirrhotic rats. Its role in the development of spontaneous bacterial peritonitis," Gut, vol. 35, no. 11, pp. 1648-1652, 1994.

[17] J. M. Llovet, R. Bartolí, F. March et al., “Translocated intestinal bacteria cause spontaneous bacterial peritonitis in cirrhotic rats: molecular epidemiologic evidence," Journal of Hepatology, vol. 28, no. 2, pp. 307-313, 1998.

[18] I. Cirera, T. M. Bauer, M. Navasa et al., "Bacterial translocation of enteric organisms in patients with cirrhosis," Journal of Hepatology, vol. 34, no. 1, pp. 32-37, 2001.

[19] D.-C. Yeh, C.-C. Wu, W.-M. Ho et al., "Bacterial translocation after cirrhotic liver resection: a clinical investigation of 181 patients," Journal of Surgical Research, vol. 111, no. 2, pp. 209214, 2003.

[20] J. Such, R. Francés, C. Muoz et al., "Detection and identification of bacterial DNA in patients with cirrhosis and culturenegative, nonneutrocytic ascites," Hepatology, vol. 36, no. 1, pp. 135-141, 2002.

[21] R. Francés, C. Muñoz, P. Zapater et al., "Bacterial DNA activates cell mediated immune response and nitric oxide overproduction in peritoneal macrophages from patients with cirrhosis and ascites," Gut, vol. 53, no. 6, pp. 860-864, 2004.
[22] U. Thalhieimer, C. K. Triantes, D. N. Samonakis, D. Patch, and A. K. Burroughs, "Infection, coagulation, and variceal bleeding in cirrhosis," Gut, vol. 54, no. 4, pp. 556-563, 2005.

[23] J. Lata, J. Juránková, L. Husová et al., "Variceal bleeding in portal hypertension: bacterial infection and comparison of efficacy of intravenous and per-oral application of antibioticsa randomized trial," European Journal of Gastroenterology \& Hepatology, vol. 17, no. 10, pp. 1105-1110, 2005.

[24] A. L. Salzman, M. J. Menconi, N. Unno et al., "Nitric oxide dilates tight junctions and depletes ATP in cultured Caco2BBe intestinal epithelial monolayers," American Journal of Physiology, vol. 268, no. 2, pp. G361-G373, 1995.

[25] J. Such, J. V. Guardiola, J. de Juan et al., "Ultrastructural characteristics of distal duodenum mucosa in patients with cirrhosis," European Journal of Gastroenterology \& Hepatology, vol. 14, no. 4, pp. 371-376, 2002.

[26] V. Misra, S. P. Misra, M. Dwivedi, and S. C. Gupta, "Histomorphometric study of portal hypertensive enteropathy," American Journal of Clinical Pathology, vol. 108, no. 6, pp. 652-657, 1997.

[27] N. Hashimoto and H. Ohyanagi, "Effect of acute portal hypertension on gut mucosa," Hepato-Gastroenterology, vol. 49, no. 48, pp. 1567-1570, 2002.

[28] T. Inamura, S. Miura, Y. Tsuzuki et al., "Alteration of intestinal intraepithelial lymphocytes and increased bacterial translocation in a murine model of cirrhosis," Immunology Letters, vol. 90, no. 1, pp. 3-11, 2003.

[29] A. Ramachandran and K. A. Balasubramanian, "Intestinal dysfunction in liver cirrhosis: its role in spontaneous bacterial peritonitis," Journal of Gastroenterology and Hepatology (Australia), vol. 16, no. 6, pp. 607-612, 2001.

[30] R. B. Sartor, "Therapeutic manipulation of the enteric microflora in inflammatory bowel diseases: antibiotics, probiotics, and prebiotics," Gastroenterology, vol. 126, no. 6, pp. 1620-1633, 2004.

[31] S. E. Jones and J. Versalovic, "Probiotic Lactobacillus reuteri biofilms produce antimicrobial and anti-inflammatory factors," BMC Microbiology, vol. 9, article 35, 2009.

[32] F. Yan, H. Cao, T. L. Cover, R. Whitehead, M. K. Washington, and D. B. Polk, "Soluble proteins produced by probiotic bacteria regulate intestinal epithelial cell survival and growth," Gastroenterology, vol. 132, no. 2, pp. 562-575, 2007.

[33] J. McCarthy, L. O’Mahony, L. O’Callaghan et al., "Double blind, placebo controlled trial of two probiotic strains in interleukin 10 knockout mice and mechanistic link with cytokine balance," Gut, vol. 52, no. 7, pp. 975-980, 2003.

[34] N. Borruel, M. Carol, F. Casellas et al., "Increased mucosal tumour necrosis factor $\alpha$ production in Crohn's disease can be downregulated ex vivo by probiotic bacteria," Gut, vol. 51, no. 5, pp. 659-664, 2002.

[35] G. Dalmasso, F. Cottrez, V. Imbert et al., "Saccharomyces boulardii inhibits inflammatory bowel disease by trapping $\mathrm{T}$ cells in mesenteric lymph nodes," Gastroenterology, vol. 131, no. 6, pp. 1812-1825, 2006.

[36] C. Rousseaux, X. Thuru, A. Gelot et al., "Lactobacillus acidophilus modulates intestinal pain and induces opioid and cannabinoid receptors," Nature Medicine, vol. 13, no. 1, pp. 3537, 2007.

[37] A. Rimola, G. García-Tsao, M. Navasa et al., "Diagnosis, treatment and prophylaxis of spontaneous bacterial peritonitis: a consensus document," Journal of Hepatology, vol. 32, no. 1, pp. 142-153, 2000. 
[38] G. Garcia-Tsao, "Current management of the complications of cirrhosis and portal hypertension: variceal hemorrhage, ascites, and spontaneous bacterial peritonitis," Gastroenterology, vol. 120, no. 3, pp. 726-748, 2001.

[39] J. Versalovic, "Probiotics: intestinal gatekeeping, immunomodulation, and hepatic injury," Hepatology, vol. 46, no. 3, pp. 618621, 2007.

[40] J. Lata, I. Novotný, V. Příbramská et al., “The effect of probiotics on gut flora, level of endotoxin and Child-Pugh score in cirrhotic patients: results of a double-blind randomized study," European Journal of Gastroenterology \& Hepatology, vol. 19, no. 12, pp. 1111-1113, 2007.

[41] R. Wiest and G. Garcia-Tsao, "Bacterial translocation (BT) in cirrhosis," Hepatology, vol. 41, no. 3, pp. 422-433, 2005.

[42] N. Rayes, D. Seehofer, T. Theruvath et al., "Supply of preand probiotics reduces bacterial infection rates after liver transplantation-a randomized, double-blind trial," American Journal of Transplantation, vol. 5, no. 1, pp. 125-130, 2005.

[43] T. M. Bauer, J. Fernández, M. Navasa, J. Vila, and J. Rodés, "Failure of Lactobacillus spp. to prevent bacterial translocation in a rat model of experimental cirrhosis," Journal of Hepatology, vol. 36, no. 4, pp. 501-506, 2002.

[44] C. Pande, A. Kumar, and S. K. Sarin, "Addition of probiotics to norfloxacin does not improve efficacy in the prevention of spontaneous bacterial peritonitis: a double-blind placebocontrolled randomized-controlled trial," European Journal of Gastroenterology \& Hepatology, vol. 24, no. 7, pp. 831-839, 2012.

[45] W. A. Macbeth, E. Kass, and W. V. Mcdermott Jr., "Treatment of hepatic encephalopathy by alteration of intestinal flora with Lactobacillus Acidophilus," The Lancet, vol. 285, no. 7382, pp. 399-403, 1965.

[46] A. E. Read, C. F. McCarthy, K. W. Heaton, and J. Laidlaw, "Lactobacillus acidophilus (Enpac) in treatment of hepatic encephalopathy," British medical journal, vol. 1, no. 5498, pp. 1267-1269, 1966.

[47] C. Loguercio, R. Abbiati, M. Rinaldi, A. Romano, C. D. V. Blanco, and M. Coltorti, "Long-term effects of Enterococcus faecium SF68 versus lactulose in the treatment of patients with cirrhosis and grade 1-2 hepatic encephalopathy," Journal of Hepatology, vol. 23, no. 1, pp. 39-46, 1995.

[48] Q. Liu, Z. P. Duan, D. K. Ha, S. Bengmark, J. Kurtovic, and S. M. Riordan, "Synbiotic modulation of gut flora: effect on minimal hepatic encephalopathy in patients with cirrhosis," Hepatology, vol. 39, no. 5, pp. 1441-1449, 2004.

[49] M. Malaguarnera, F. Greco, G. Barone, M. P. Gargante, and M. A. Toscano, "Bifidobacterium longum with fructo-oligosaccharide (FOS) treatment in minimal hepatic encephalopathy: a randomized, double-blind, placebo-controlled study," Digestive Diseases and Sciences, vol. 52, no. 11, pp. 3259-3265, 2007.

[50] M. Malaguarnera, M. P. Gargante, G. Malaguarnera et al., "Bifidobacterium combined with fructo-oligosaccharide versus lactulose in the treatment of patients with hepatic encephalopathy," European Journal of Gastroenterology \& Hepatology, vol. 22, no. 2, pp. 199-206, 2010.

[51] R. G. McGee, A. Bakens, K. Wiley, S. M. Riordan, and A. C. Webster, "Probiotics for patients with hepatic encephalopathy," The Cochrane Database of Systematic Reviews, no. 11, Article ID CD008716, 2011.

[52] S. Saji, S. Kumar, and V. Thomas, "A randomized double blind placebo controlled trial of probiotics in minimal hepatic encephalopathy," Tropical Gastroenterology, vol. 32, no. 2, pp. 128-132, 2011.
[53] M. K. Lunia, B. C. Sharma, P. Sharma, S. Sachdeva, and S. Srivastava, "Probiotics prevent hepatic encephalopathy in patients with cirrhosis: a randomized controlled trial," Clinical Gastroenterology and Hepatology, vol. 12, no. 6, pp. 1003-1008, 2014.

[54] A. Agrawal, B. C. Sharma, P. Sharma, and S. K. Sarin, "Secondary prophylaxis of hepatic encephalopathy in cirrhosis: an open-label, randomized controlled trial of lactulose, probiotics, and no therapy," The American Journal of Gastroenterology, vol. 107, no. 7, pp. 1043-1050, 2012.

[55] C. Loguercio, A. Federico, C. Tuccillo et al., "Beneficial effects of a probiotic VSL\#3 on parameters of liver dysfunction in chronic liver diseases," Journal of Clinical Gastroenterology, vol. 39, no. 6, pp. 540-543, 2005.

[56] F. P. Vleggaar, J. F. Monkelbaan, and K. J. van Erpecum, "Probiotics in primary sclerosing cholangitis: a randomized placebo-controlled crossover pilot study," European Journal of Gastroenterology \& Hepatology, vol. 20, no. 7, pp. 688-692, 2008.

[57] Y.-M. Lee and M. M. Kaplan, "Primary sclerosing cholangitis," The New England Journal of Medicine, vol. 332, no. 14, pp. 924933, 1995.

[58] B. J. Rembacken, A. M. Snelling, P. M. Hawkey, D. M. Chalmers, and A. T. R. Axon, "Non-pathogenic Escherichia coli versus mesalazine for the treatment of ulcerative colitis: a randomised trial," The Lancet, vol. 354, no. 9179, pp. 635-639, 1999.

[59] P. Gionchetti, F. Rizzello, U. Helwig et al., "Prophylaxis of pouchitis onset with probiotic therapy: a double-blind, placebocontrolled trial," Gastroenterology, vol. 124, no. 5, pp. 1202-1209, 2003.

[60] A. J. Wigg, I. C. Roberts-Thomson, R. B. Dymock, P. J. McCarthy, R. H. Grose, and A. G. Cummins, "The role of small intestinal bacterial overgrowth, intestinal permeability, endotoxaemia, and tumour necrosis factor $\alpha$ in the pathogenesis of non-alcoholic steatohepatitis," Gut, vol. 48, no. 2, pp. 206-211, 2001.

[61] E. J. Drenick, J. Fisler, and D. Johnson, "Hepatic steatosis after intestinal bypass-prevention and reversal by metronidazole, irrespective of protein-calorie malnutrition," Gastroenterology, vol. 82, no. 3, pp. 535-548, 1982.

[62] S. Q. Yang, H. Z. Lin, M. D. Lane, M. Clemens, and A. M. Diehl, "Obesity increases sensitivity to endotoxin liver injury: implications for the pathogenesis of steatohepatitis," Proceedings of the National Academy of Sciences of the United States of America, vol. 94, no. 6, pp. 2557-2562, 1997.

[63] F. Lirussi, E. Mastropasqua, S. Orando, and R. Orlando, "Probiotics for non-alcoholic fatty liver disease and/or steatohepatitis," Cochrane Database of Systematic Reviews, vol. 1, Article ID CD005165, 2007.

[64] S. F. Solga and A. M. Diehl, "Non-alcoholic fatty liver disease: lumen-liver interactions and possible role for probiotics," Journal of Hepatology, vol. 38, no. 5, pp. 681-687, 2003.

[65] R. Aller, D. A. de Luis, O. Izaola et al., "Effect of a probiotic on liver aminotransferases in nonalcoholic fatty liver disease patients: a double blind randomized clinical trial," European Review for Medical and Pharmacological Sciences, vol. 15, no. 9, pp. 1090-1095, 2011.

[66] P. Vajro, C. Mandato, M. R. Licenziati et al., "Effects of Lactobacillus rhamnosus strain GG in pediatric obesity-related liver disease," Journal of Pediatric Gastroenterology and Nutrition, vol. 52, no. 6, pp. 740-743, 2011.

[67] M. Malaguarnera, M. Vacante, T. Antic et al., "Bifidobacterium longum with fructo-oligosaccharides in patients with non 
alcoholic steatohepatitis," Digestive Diseases and Sciences, vol. 57, no. 2, pp. 545-553, 2012.

[68] V. W.-S. Wong, G. L.-H. Wong, A. M.-L. Chim et al., "Treatment of nonalcoholic steatohepatitis with probiotics. a proof-ofconcept study," Annals of Hepatology, vol. 12, no. 2, pp. 256-262, 2013.

[69] Y.-Y. Ma, L. Li, C.-H. Yu, Z. Shen, L.-H. Chen, and Y.-M. Li, "Effects of probiotics on nonalcoholic fatty liver disease: a metaanalysis," World Journal of Gastroenterology, vol. 19, no. 40, pp. 6911-6918, 2013.

[70] A. Gramenzi, F. Caputo, M. Biselli et al., "Review article: alcoholic liver disease-pathophysiological aspects and risk factors," Alimentary Pharmacology \& Therapeutics, vol. 24, no. 8, pp. 1151-1161, 2006.

[71] G. Malaguarnera, M. Giordano, G. Nunnari, G. Bertino, and M. Malaguarnera, "Gut microbiota in alcoholic liver disease: pathogenetic role and therapeutic perspectives," World Journal of Gastroenterology, article 9724, 2014.

[72] R. G. Thurman II, "Alcoholic liver injury involves activation of Kupffer cells by endotoxin," The American Journal of Physiology, vol. 275, pp. G605-G611, 1998.

[73] J. B. Hoek and J. G. Pastorino, "Ethanol, oxidative stress, and cytokine-induced liver cell injury," Alcohol, vol. 27, no. 1, pp. 6368, 2002.

[74] H. Tsukamoto, Y. Takei, C. J. McClain et al., "How is the liver primed or sensitized for alcoholic liver disease?" Alcoholism: Clinical and Experimental Research, vol. 25, no. 5, pp. 171S-181S, 2001.

[75] E. A. Mutlu, P. M. Gillevet, H. Rangwala et al., "Colonic microbiome is altered in alcoholism," American Journal of Physiology-Gastrointestinal and Liver Physiology, vol. 302, no. 9, pp. G966-G978, 2012.

[76] I. A. Kirpich, N. V. Solovieva, S. N. Leikhter et al., "Probiotics restore bowel flora and improve liver enzymes in human alcohol-induced liver injury: a pilot study," Alcohol, vol. 42, no. 8, pp. 675-682, 2008.

[77] V. Stadlbauer, R. P. Mookerjee, S. Hodges, G. A. K. Wright, N. A. Davies, and R. Jalan, "Effect of probiotic treatment on deranged neutrophil function and cytokine responses in patients with compensated alcoholic cirrhosis," Journal of Hepatology, vol. 48, no. 6, pp. 945-951, 2008.

[78] R. P. Mookerjee, V. Stadlbauer, S. Lidder et al., "Neutrophil dysfunction in alcoholic hepatitis superimposed on cirrhosis is reversible and predicts the outcome," Hepatology, vol. 46, no. 3, pp. 831-840, 2007.

[79] S. Jayakumar, M. Carbonneau, N. Hotte et al., "VSL\#3 probiotic therapy does not reduce portal pressures in patients with decompensated cirrhosis," Liver International, vol. 33, no. 10, pp. 1470-1477, 2013.

[80] N. Gupta, A. Kumar, P. Sharma, V. Garg, B. C. Sharma, and S. K. Sarin, "Effects of the adjunctive probiotic VSL\#3 on portal haemodynamics in patients with cirrhosis and large varices: a randomized trial," Liver International, vol. 33, no. 8, pp. 11481157, 2013.

[81] D. Rincón, J. Vaquero, A. Hernando et al., “Oral probiotic VSL\#3 attenuates the circulatory disturbances of patients with cirrhosis and ascites," Liver International, vol. 34, no. 10, pp. 1504-1512, 2014.

[82] P. Tandon, K. Moncrief, K. Madsen et al., "Effects of probiotic therapy on portal pressure in patients with cirrhosis: a pilot study," Liver International, vol. 29, no. 7, pp. 1110-1115, 2009.
[83] M. G. Besselink, H. C. van Santvoort, E. Buskens et al., "Probiotic prophylaxis in predicted severe acute pancreatitis: a randomised, double-blind, placebo-controlled trial," The Lancet, vol. 371, no. 9613, pp. 651-659, 2008. 


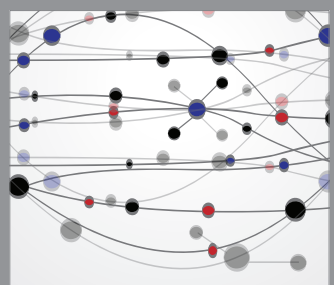

The Scientific World Journal
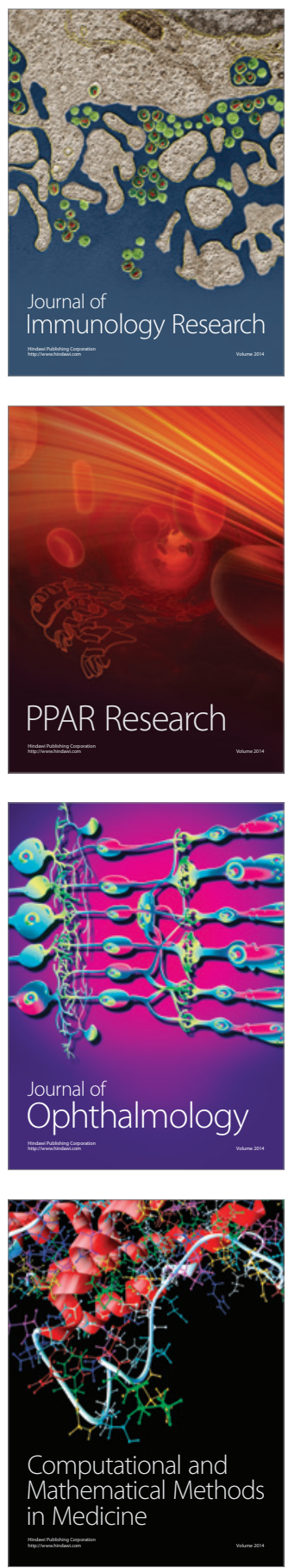

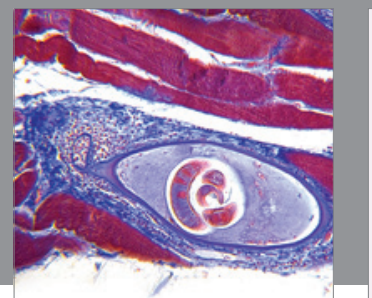

Gastroenterology

Research and Practice
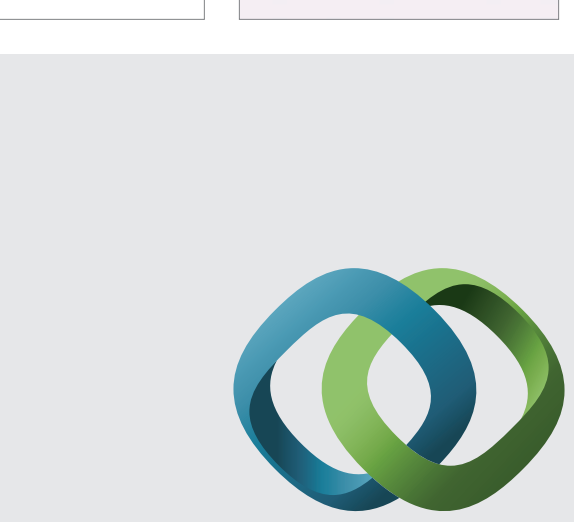

\section{Hindawi}

Submit your manuscripts at

http://www.hindawi.com
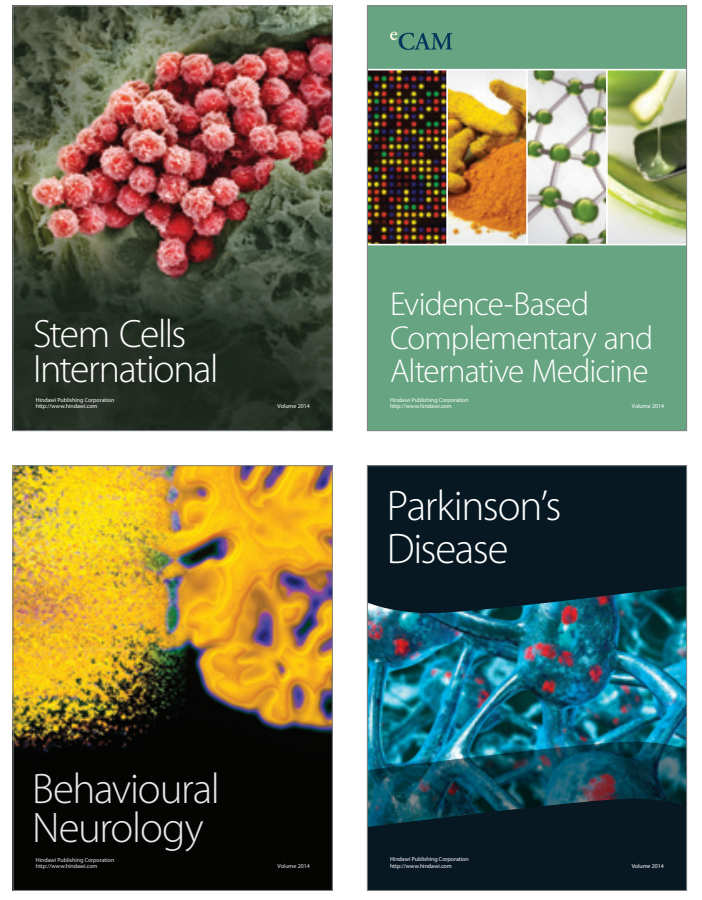
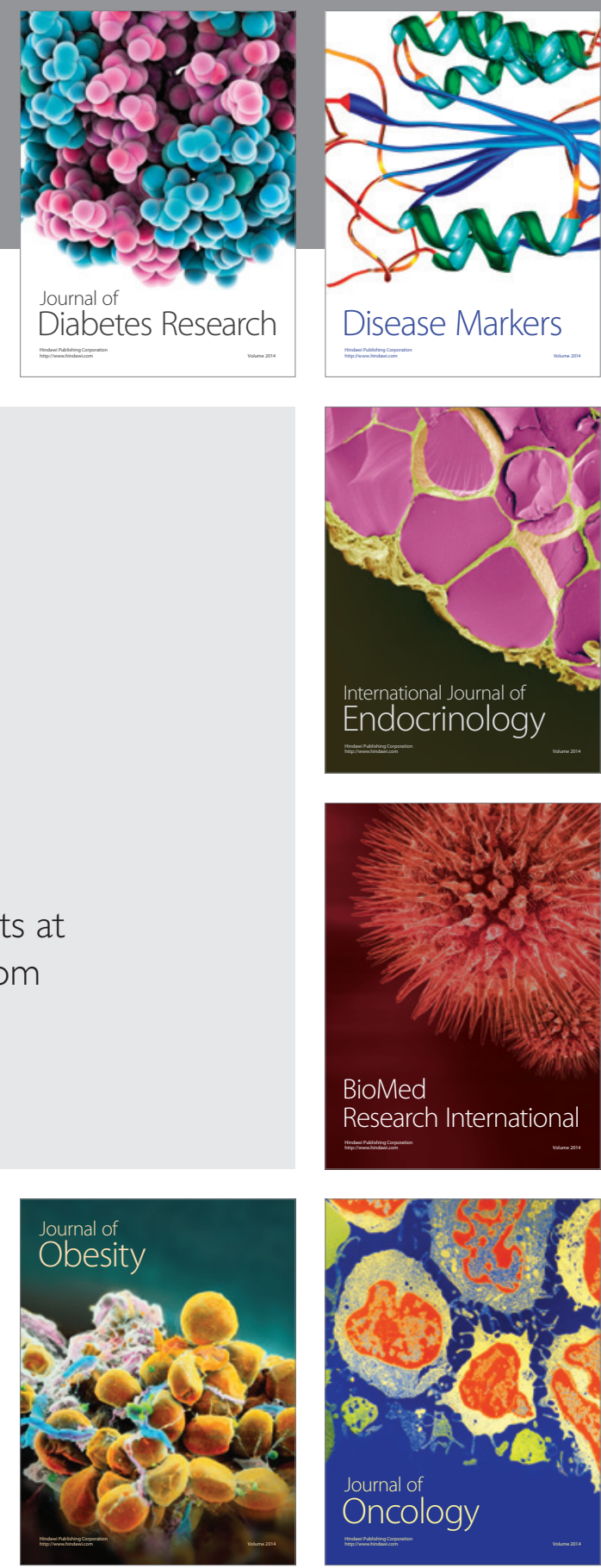

Disease Markers
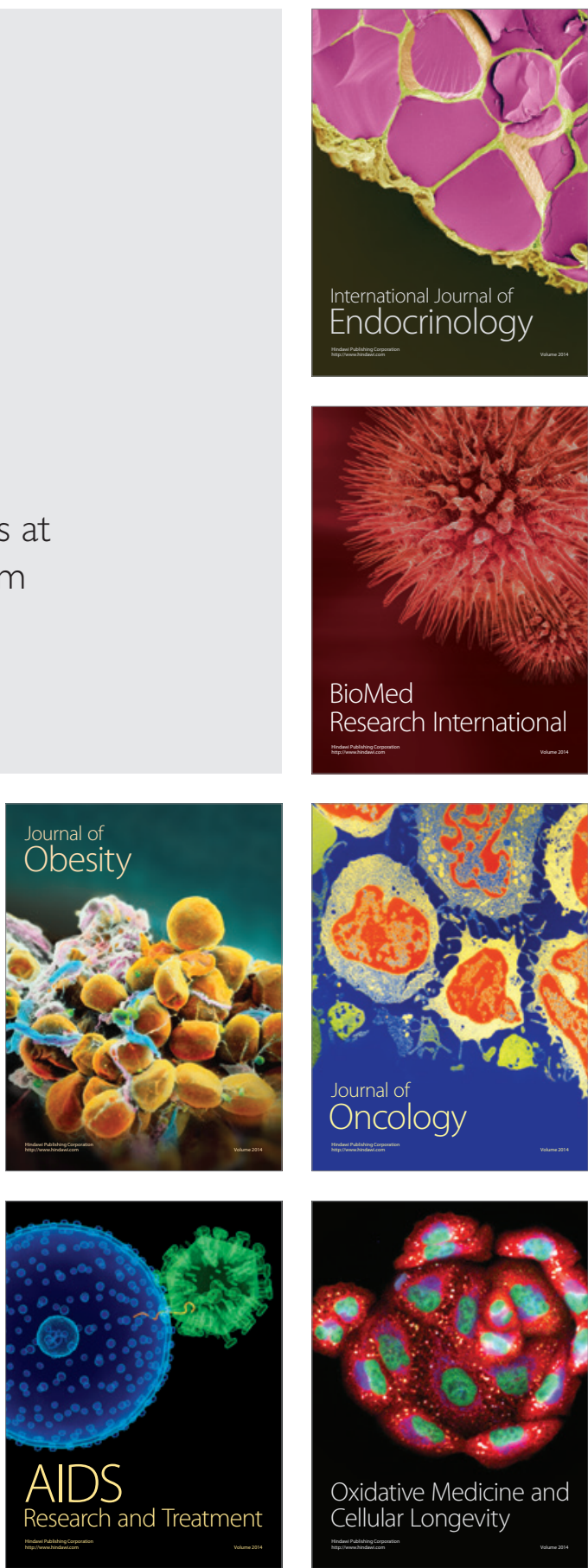